\title{
Nomogram predicting pulmonary metastasis of hepatocellular carcinoma after liver transplantation
}

\author{
Li-Feng Huang ${ }^{1, *}$, Ping Wan ${ }^{1, *}$, Dong-Wei $X \mathbf{u}^{1, *}{ }^{,}$, Seogsong Jeong ${ }^{1}$, Ming-Xuan Feng ${ }^{1}$, \\ Jian-Jun Zhang ${ }^{1}$ and Qiang Xia ${ }^{1}$ \\ ${ }^{1}$ Department of Hepatic Surgery, Ren Ji Hospital, School of Medicine, Shanghai Jiao Tong University, Shanghai 200127, China \\ *These authors have contributed equally to this work
}

Correspondence to: Qiang Xia, email: xiaqiang@shsmu.edu.cn

Keywords: nomogram; liver transplantation; hepatocellular carcinoma; prognosis; pulmonary metastasis

Received: June 09, $2017 \quad$ Accepted: September 21, 2017 Published: December 19, 2017

Copyright: Huang et al. This is an open-access article distributed under the terms of the Creative Commons Attribution License 3.0 (CC BY 3.0), which permits unrestricted use, distribution, and reproduction in any medium, provided the original author and source are credited.

\section{ABSTRACT}

\begin{abstract}
A novel prognostic nomogram predicting post-transplant pulmonary metastasis was established with a primary cohort of 308 HCC patients who received liver transplantation between 2007 and 2011 at Ren Ji Hospital. The C-indexes for predicting pulmonary metastasis was 0.85 . The calibration curves fitted well between the predicted and actual outcomes. The decision curve analysis indicated that our nomogram was the optimal decision-making strategy for PM prediction compared to Milan, University of California San Franscisco, and up-to-seven criteria. These results were further validated by data from 103 patients who underwent liver transplantation between 2011 and 2012 at the same institution. In conclusion, our nomogram could be used as an effective tool to predict PM after liver transplantation.
\end{abstract}

\section{INTRODUCTION}

Hepatocellular carcinoma (HCC) is the sixth most common cancer and a primary cause of cancer-related mortality [1]. Liver transplantation (LT) is an optimal therapy for liver cancer, because it can radically remove the primary tumor and treat underlying liver diseases, such as primary biliary cirrhosis (PBC) and hepatitis B virus (HBV)-associated cirrhosis. However, tumor recurrence after LT is frequently extrahepatic and could significantly influence the survival outcomes of patients. Pulmonary metastasis (PM) accounts for nearly half of all extrahepatic metastases after LT [2-4].

PM following curative LT for HCC indicates a poor prognosis. However, postoperative management of PM could significantly prolong patient survival. Several institutions have suggested that pneumonectomy for PM in patients with HCC following LT may improve longterm survival, but this procedure must be performed delicately in highly-selected patients, especially patients with maximum tumor size of the pulmonary metastasis $<3 \mathrm{~cm}$ [5-7]. Radiofrequency ablation (RFA) for lung metastasis of HCC was recently reported as a minimally invasive treatment with an effectiveness rate of $92 \%$ and improved survival rate $[8,9]$. Jang et al. demonstrated that the application of conformal radiotherapy and tomotherapy, including helical tomotherapy, increased the partial/complete remission rate of PM [10]. Despite advances in the treatment of PM, approaches for accurate prediction of PM incidence after LT remain insufficient. Accurate identification of high-risk patients may lead to early detection of PM and prolong overall survival.

Precise prediction of postoperative PM is challenging due to the multitude of incidence factors. Existing clinical staging systems can be applied to predict PM development [11-13], but were not developed for this purpose. The nomogram is an established and accurate model for clinical prediction [14-16]. In this study, we developed a nomogram to predict the postoperative development of PM in patients with HCC. 


\section{RESULTS}

\section{Clinicopathological characteristics}

The clinicopathological characteristics of primary and validation cohorts are summarized in Tables 1 and 2. The majority of the patients were male (86.1\%), hepatitis B surface antigen-positive $(89.8 \%)$, and single nodule $(72.7 \%)$. No statistical difference was found in the clinicopathological characteristics of the cohorts.

\section{Clinical outcome in primary cohort}

The median follow-up of the primary cohort was 48 months (range, 1-97) and the median time to the development of PM was 23 month (range, 1-94). The postoperative overall survival (OS) and tumor recurrence rates were $71.5 \%, 55.9 \%, 52.2 \%$, and $33.1 \%, 40.4 \%$, $42.7 \%$ at 1,3 , and 5 years, respectively. Among patients with postoperative recurrence or metastasis, 72 patients were diagnosed with PM before or simultaneously with other recurrences: PM only ( $\mathrm{n}=35), \mathrm{PM}$ with intrahepatic recurrence $(\mathrm{n}=13), \mathrm{PM}$ with abdomen/pelvis metastasis $(\mathrm{n}=8), \mathrm{PM}$ with adrenal gland metastasis $(\mathrm{n}=2), \mathrm{PM}$ with lymph gland metastasis $(\mathrm{n}=5)$, PM with bone metastasis $(\mathrm{n}=7)$, or PM with brain metastasis $(\mathrm{n}=2)$. In addition, 21 patients had intrahepatic recurrence only. Extrapulmonary metastases were demonstrated in 23 patients: abdomen/ pelvis $(n=7)$, adrenal gland $(n=2)$, lymph gland $(n=3)$, bone $(n=10)$, and brain $(n=1)$. Intrahepatic recurrence combined with distant metastases (except lung) were found in 16 patients.

\section{Construction of nomogram}

Univariate and multivariate analyses demonstrated that preoperative serum AFP, vascular invasion, within or downstaged to Milan criteria, tumor diameter, tumor nodules, and tumor differentiation were found to be independent factors that influenced the incidence of PM (Table 3). These six variables were included in the nomogram (Figure 1). The model was accurate with a

Points

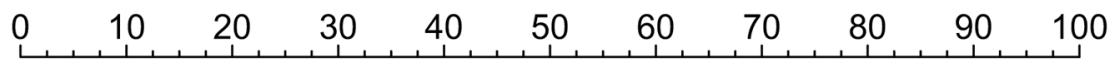

$\operatorname{AFP}(\mathrm{ng} / \mathrm{ml})$

Vascular invasion

Milan

Tumor size $(\mathrm{cm})$

Nodules

Differentiation

Total Points

1-year PM probability

3-year PM probability

5-year PM probability

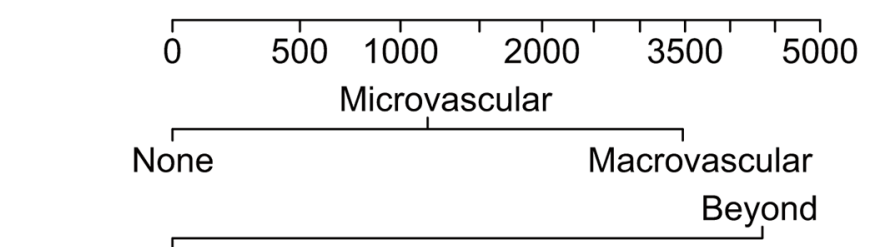

Within or Downstaged to

Beyond

\section{Whin or Downstaged to}
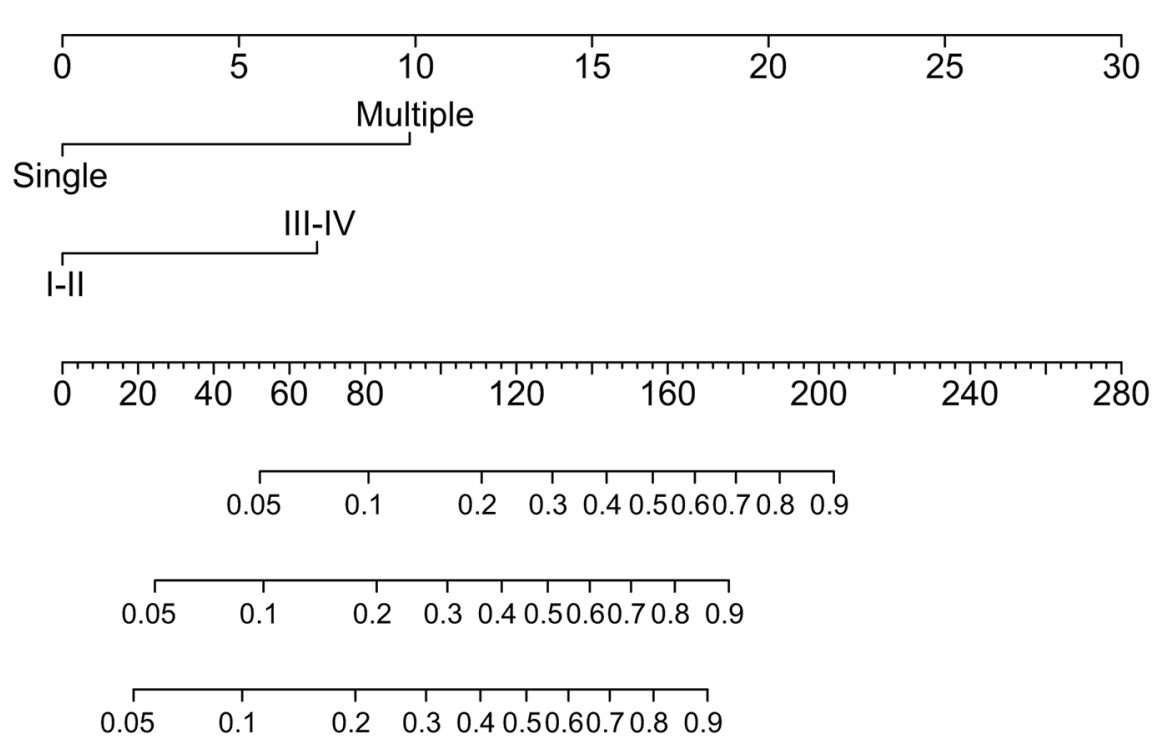

Figure 1: Nomogram for PM prediction after LT. AFP, serum $\alpha$-fetoprotein level before LT; Milan, tumor within or downstaged to the Milan criteria before LT; Differentiation, tumor histologic differentiation. 
Table 1: Baseline patients characteristics

\begin{tabular}{|c|c|c|c|c|}
\hline \multirow[t]{2}{*}{ Variables } & \multicolumn{2}{|c|}{ Primary cohort } & \multicolumn{2}{|c|}{ Validation cohort } \\
\hline & $\begin{array}{c}\text { No. of } \\
\text { patients }\end{array}$ & $\%$ & $\begin{array}{c}\text { No. of } \\
\text { patients }\end{array}$ & $\%$ \\
\hline No. of patients & 308 & 100 & 103 & 100 \\
\hline \multicolumn{5}{|l|}{ Age, years } \\
\hline Median & 51 & & 50 & \\
\hline Range & $28-72$ & & $30-69$ & \\
\hline \multicolumn{5}{|l|}{ Sex } \\
\hline Male & 262 & 85.1 & 92 & 89.3 \\
\hline Female & 46 & 14.9 & 11 & 10.7 \\
\hline \multicolumn{5}{|l|}{ HBsAg } \\
\hline Negative & 27 & 8.8 & 15 & 14.6 \\
\hline Positive & 281 & 91.2 & 88 & 85.4 \\
\hline \multicolumn{5}{|l|}{ HCV-Ab } \\
\hline Negative & 300 & 97.4 & 99 & 96.1 \\
\hline Positive & 8 & 2.6 & 4 & 3.9 \\
\hline \multicolumn{5}{|l|}{ PT, second } \\
\hline Median & 14.5 & & 14.2 & \\
\hline Range & $10.6-35.7$ & & $9.4-31.7$ & \\
\hline \multicolumn{5}{|l|}{$\mathbf{A L B}, \mathbf{g} / \mathbf{L}$} \\
\hline Median & 35.6 & & 35.9 & \\
\hline Range & $16-63.8$ & & $21-55$ & \\
\hline \multicolumn{5}{|l|}{$\mathbf{A L T}, \mathbf{U} / \mathbf{L}$} \\
\hline Median & 42.2 & & 50.8 & \\
\hline Range & $10-217$ & & $9-295$ & \\
\hline \multicolumn{5}{|l|}{ AFP, ng/mL } \\
\hline Median & 654.4 & & 794.3 & \\
\hline Range & $1-4800$ & & $1.3-4789$ & \\
\hline \multicolumn{5}{|l|}{ CA19-9, U/mL } \\
\hline Median & 58.7 & & 46.1 & \\
\hline Range & $0.1-568$ & & $0.8-423$ & \\
\hline \multicolumn{5}{|l|}{ MELD score } \\
\hline Median & 12.6 & & 10.8 & \\
\hline Range & $6.4-36.1$ & & $6.4-29.1$ & \\
\hline \multicolumn{5}{|l|}{ Cirrhosis } \\
\hline No & 45 & 14.6 & 9 & 8.7 \\
\hline Yes & 263 & 85.4 & 94 & 91.3 \\
\hline \multicolumn{5}{|c|}{ Surgical intervention } \\
\hline DDLT & 266 & 86.4 & 91 & 88.3 \\
\hline LDLT & 42 & 13.6 & 12 & 11.7 \\
\hline
\end{tabular}

Abbreviations: AFP, alpha-fetoprotein; ALB, albumin; ALT, alanine aminotransferase; CA19-9, carbohydrate antigen 19-9; DDLT, deceased-donor liver transplantation; HBsAg, hepatitis B surface antigen; HCV, hepatitis C virus; LDLT, livingdonor liver transplantation; MELD, model for end-stage liver disease; PT, prothrombin time. 
Table 2: Pathological characteristics of tumor

\begin{tabular}{|c|c|c|c|c|}
\hline \multirow[t]{2}{*}{ Variables } & \multicolumn{2}{|c|}{ Primary cohort } & \multicolumn{2}{|c|}{ Validation cohort } \\
\hline & $\begin{array}{c}\text { No. of } \\
\text { patients }\end{array}$ & $\%$ & $\begin{array}{c}\text { No. of } \\
\text { patients }\end{array}$ & $\%$ \\
\hline No. of patients & 308 & 100 & 103 & 100 \\
\hline \multicolumn{5}{|l|}{ Tumor size, cm } \\
\hline $\begin{array}{l}\text { Median } \\
\text { Range }\end{array}$ & $\begin{array}{c}5.7 \\
1-30\end{array}$ & & $\begin{array}{c}5.1 \\
1-18\end{array}$ & \\
\hline \multicolumn{5}{|l|}{ Nodules } \\
\hline $\begin{array}{l}\text { Single } \\
\text { Multiple }\end{array}$ & $\begin{array}{c}229 \\
79\end{array}$ & $\begin{array}{l}74.4 \\
25.6\end{array}$ & $\begin{array}{l}70 \\
33\end{array}$ & $\begin{array}{l}68.0 \\
32.0\end{array}$ \\
\hline \multicolumn{5}{|l|}{ Capsule } \\
\hline $\begin{array}{l}\text { Incomplete } \\
\text { Complete }\end{array}$ & $\begin{array}{c}260 \\
48\end{array}$ & $\begin{array}{l}84.4 \\
15.6\end{array}$ & $\begin{array}{l}87 \\
16\end{array}$ & $\begin{array}{l}84.5 \\
15.5\end{array}$ \\
\hline \multicolumn{5}{|l|}{ Vascular invasion } \\
\hline $\begin{array}{l}\text { None } \\
\text { Microvascular invasion } \\
\text { Macrovascular invasion }\end{array}$ & $\begin{array}{c}240 \\
30 \\
38\end{array}$ & $\begin{array}{c}77.9 \\
9.7 \\
12.3\end{array}$ & $\begin{array}{l}77 \\
11 \\
15\end{array}$ & $\begin{array}{l}74.8 \\
10.7 \\
14.6\end{array}$ \\
\hline \multicolumn{5}{|l|}{ Differentiation } \\
\hline $\begin{array}{l}\text { I-II } \\
\text { III-IV }\end{array}$ & $\begin{array}{c}252 \\
56\end{array}$ & $\begin{array}{l}81.8 \\
18.2\end{array}$ & $\begin{array}{l}82 \\
21\end{array}$ & $\begin{array}{l}79.6 \\
20.4\end{array}$ \\
\hline \multicolumn{5}{|l|}{ Mlian criteria } \\
\hline $\begin{array}{l}\text { Within }{ }^{\dagger} \\
\text { Beyond }\end{array}$ & $\begin{array}{l}185 \\
123\end{array}$ & $\begin{array}{l}60.1 \\
39.9\end{array}$ & $\begin{array}{l}58 \\
45\end{array}$ & $\begin{array}{l}56.3 \\
43.7\end{array}$ \\
\hline
\end{tabular}

Includes tumor within and downstaged to Milan criteria before Liver transplantation. Microvascular invasion indicates number of patients with microvascular invasion, but without macrovascular invasion. Macrovascular invasion includes both the patients with or without microvascular invasion.

concordance index (C-index) of 0.85 . The calibration plot indicated a strong correlation between actual PM probability and predicted PM probability (Figure 2A and 2B).

\section{Validation of nomogram}

In the validation cohort, the median follow-up was 33 months (range, 1-44). The median time to the detection of PM was 21 months (range, 1-40). The OS and recurrence rates at 1 and 3 -years were $72.8 \%, 57.6 \%$, and $32.4 \%, 46.5 \%$, respectively. Forty-eight patients had recurrence or metastasis after LT: PM (either before or with concomitant metastasis, $\mathrm{n}=25$ ), intrahepatic recurrence only $(n=9)$, extrapulmonary metastases only $(\mathrm{n}=10)$, and intrahepatic recurrence combined with distant metastases excluding lung $(n=4)$. Among the 25 patients with postoperative PM, 11 patients presented with PM only, 5 patients presented PM with concomitant intrahepatic recurrence, 2 patients presented PM with concomitant abdomen/pelvis metastasis, 3 patients presented PM with concomitant lymph gland metastasis, and 4 patients presented PM with concomitant bone metastasis. The nomogram showed a $\mathrm{C}$-index of 0.83 with a well-fitted calibration plot (Figure 2C).

\section{Comparison of nomogram}

In our study, the nomogram demonstrates the highest curve compared to Milan, UCSF, and up-to seven criteria, revealing that it is the optimal decision-making strategy for PM prediction [11-13] (Figure 3). 
Table 3: Independent risk factors predicting PM in the primary cohort

\begin{tabular}{|c|c|c|c|c|c|c|}
\hline \multirow[t]{2}{*}{ Variables } & \multicolumn{3}{|c|}{ Univariate analysis } & \multicolumn{3}{|c|}{ Multivariate analysis } \\
\hline & HR & $95 \% \mathrm{CI}$ & $P$-value & HR & $95 \% \mathrm{CI}$ & $P$-value \\
\hline Age, years & 0.97 & 0.94-0.99 & 0.006 & & & NA \\
\hline Sex: Male vs. Female & 2.32 & $0.94-5.75$ & 0.070 & & & NA \\
\hline $\begin{array}{l}\text { HBsAg: Positive vs. } \\
\text { Negative }\end{array}$ & 1.22 & $0.49-3.02$ & 0.673 & & & NA \\
\hline PT, second & 0.94 & $0.88-1.01$ & 0.089 & & & NA \\
\hline ALB, $g / L$ & 1.02 & $0.99-1.06$ & 0.192 & & & NA \\
\hline ALT, U/L & 1.00 & $0.99-1.01$ & 0.338 & & & NA \\
\hline AFP, $n g / m L$ & 1.00 & $1.00-1.01$ & $<0.001$ & 1.00 & $1.00-1.01$ & 0.001 \\
\hline CA19-9, U/mL & 1.01 & $1.01-1.04$ & 0.074 & & & NA \\
\hline MELD score & 0.99 & $0.94-1.03$ & 0.581 & & & NA \\
\hline Cirrhosis: Yes vs. No & 1.20 & $0.60-2.42$ & 0.606 & & & NA \\
\hline Tumor size, $\mathrm{cm}$ & 1.15 & $1.12-1.19$ & $<0.001$ & 1.08 & $1.02-1.13$ & 0.006 \\
\hline $\begin{array}{l}\text { Nodules: Multiple vs. } \\
\text { Single }\end{array}$ & 1.53 & $1.18-1.98$ & 0.001 & 1.42 & $1.05-1.92$ & 0.021 \\
\hline $\begin{array}{l}\text { Capsule: Complete vs. } \\
\text { Incomplete }\end{array}$ & 0.28 & $0.10-0.76$ & 0.013 & & & NA \\
\hline Vascular invasion & 2.80 & $2.18-3.61$ & $<0.001$ & 1.90 & $1.38-2.62$ & $<0.001$ \\
\hline $\begin{array}{l}\text { Differentiation: III-IV } \\
\text { vs. I-II }\end{array}$ & 4.92 & $3.04-7.95$ & $<0.001$ & 1.81 & $1.08-3.04$ & 0.024 \\
\hline $\begin{array}{l}\text { Surgical intervention: } \\
\text { DDLT vs LDLT }\end{array}$ & 2.08 & $0.90-4.79$ & 0.087 & & & NA \\
\hline $\begin{array}{l}\text { Milan: Within }{ }^{\dagger} \text { vs. } \\
\text { Beyond }\end{array}$ & 0.07 & $0.04-1.41$ & $<0.001$ & 0.22 & $0.10-0.49$ & $<0.001$ \\
\hline
\end{tabular}

Abbreviations: AFP, alpha-fetoprotein; ALB, albumin; ALT, alanine aminotransferase; CA19-9, carbohydrate antigen 19-9; CI, confidence interval; DDLT, deceased-donor liver transplantation; HBsAg, hepatitis B surface antigen; HR, hazard ratio; LDLT, living-donor liver transplantation; MELD, model for end-stage liver disease; PT, prothrombin time.

tIncludes tumor within and downstaged to Milan criteria before Liver transplantation.

Note: Univariate and Multivariate analysis, competing risk regression model. Bold values indicate $\mathrm{P}<0.05$.

\section{DISCUSSION}

Tumor recurrence is the representative indication of poor prognosis in patients with HCC. The lung is the most common site of metastasis after LT. Successful treatment of PM by pneumonectomy and adjuvant therapy could prolong long-term survival in HCC patients $[5,7,17]$. Our nomogram was developed from comprehensive clinicopathological characteristics based on serological examinations to accurately predict the development of PM after LT. Previous reports utilizing clinical stage systems focused on the tumor diameter and number, which are influential factors for predicting tumor recurrence $[12,13]$. In addition to these two parameters, we included vascular invasion, histologic differentiation, the serum level of AFP, and tumor-downstaging to Milan criteria in our nomogram. Vascular invasion indicates that the malignancy has invaded blood vessels and represents the possibility of distant metastases. A majority of transplant centers included vascular invasion (macro- and microvascular) in their models to estimate OS or recurrence after LT 

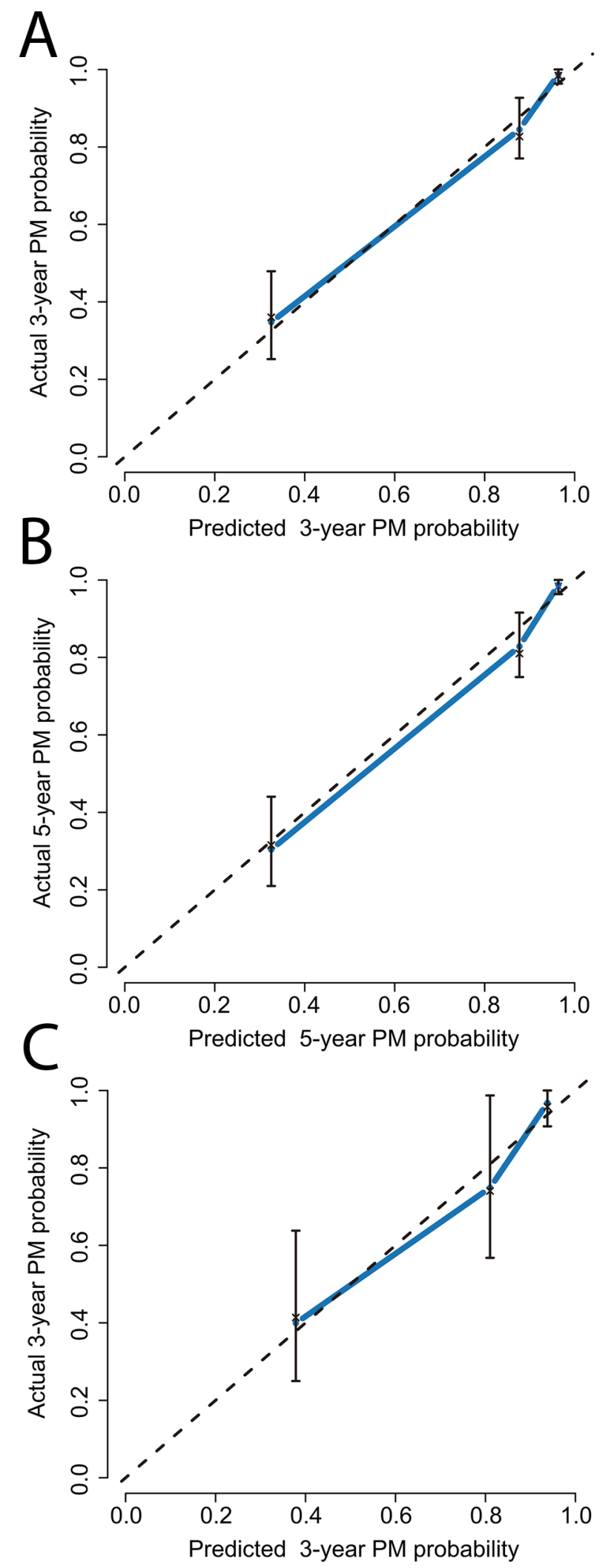

Figure 2: The calibration curve analysis for PM prediction. (A) 3 years after LT in the primary cohort; (B) 5 years after LT in primary cohort; (C) 3 years after LT in the validation cohort. 
[11, 18-19]. Histological differentiation is another critical factor in the prognosis of patients who received LT and considerable attention has been paid to its clinical application [20, 21]. Serum level of AFP is pivotal to the invasive/metastatic capacity of HCC cells and is directly associated with prognosis [22]. A recent study by Li et al. indicated that AFP levels were an independent factor that effectively predicted the occurrence of PM after hepatic resection [23]. Another study by Duvoux et al. demonstrated that the prediction of tumor recurrence was improved by including AFP level in the estimation model [24]. HCC exceeding the Milan criteria can now be downstaged before surgical operation. Improved tumor-free survival and OS has been reported in patients who received preoperative downstaging treatment and was comparable to survival outcomes of those within the Milan criteria $[25,26]$. The presence of downstaging treatment was added to our nomogram.

Prediction models have become ubiquitous for OS and tumor recurrence prediction $[15,27,28]$. The nomogram is a statistical model designed to maximize predictive accuracy and is more effective than the other models for estimating multiple clinical end points [29, 30]. Our nomogram accurately predicted PM development $(\mathrm{C}$-index $=0.85)$. DCA was used to evaluate the predictive performance of our nomogram because it is useful for assessing and comparing models that contain clinical consequences [31]. According to DCA, the nomogram is

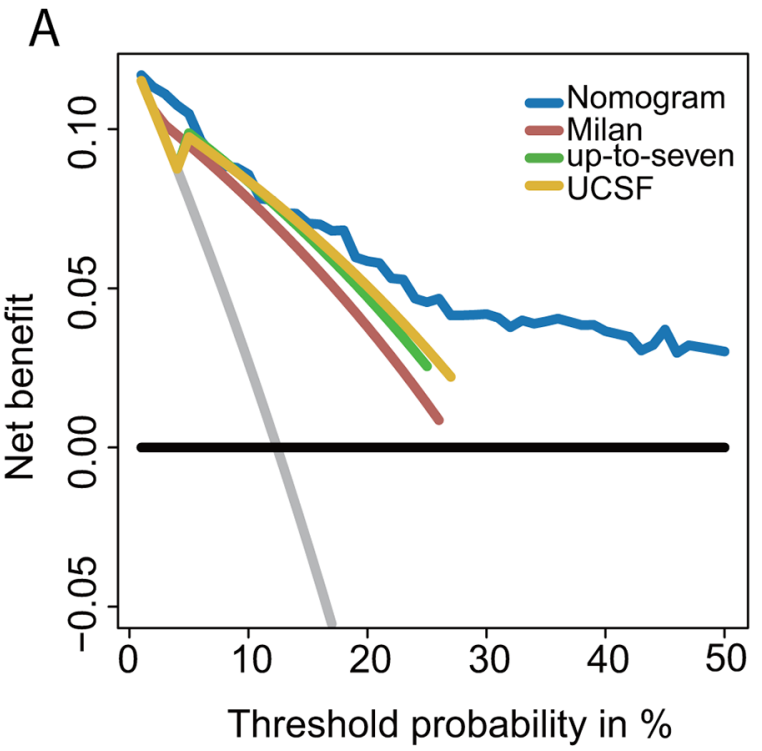

the optimal decision-making strategy compared to three well-known staging systems.

In the diagnostic procedures of PM, we could not exclude the probability of primary lung malignancy. However, the incidence of primary lung cancer in HCC patients showed a rate of less than $1 \%$ [32]. According to this incidence, the number of patients who had primary lung cancer should be no more than 2. In addition, the diagnosis of PM was based on the results from imaging studies and AFP serum level, which were sensitive enough to detect most primary lung cancers [23]. So, it is our stringent diagnostic criteria and the low incidence of primary pulmonary cancer supported the reliability of our results.

Several limitations existed: 1) as a single institutional study, large-scale randomized controlled studies are necessary to further validate this model before clinical approval; 2) the majority of our patients were HBV-associated $(89.8 \%)$ or cirrhotic $(86.9 \%)$, so the model might not be applicable to patients with other disease distributions; and 3) PM after LT was diagnosed by radiological imaging and serological examination. Although the incidence of primary lung cancer in patients with HCC is extremely low, the possibility could not be excluded entirely.

Our nomogram accurately predicted the development of PM in patients with HCC who received LT. Our results could be utilized to determine the risk index of PM in HCC patients for intensified surveillance and postoperative treatment.

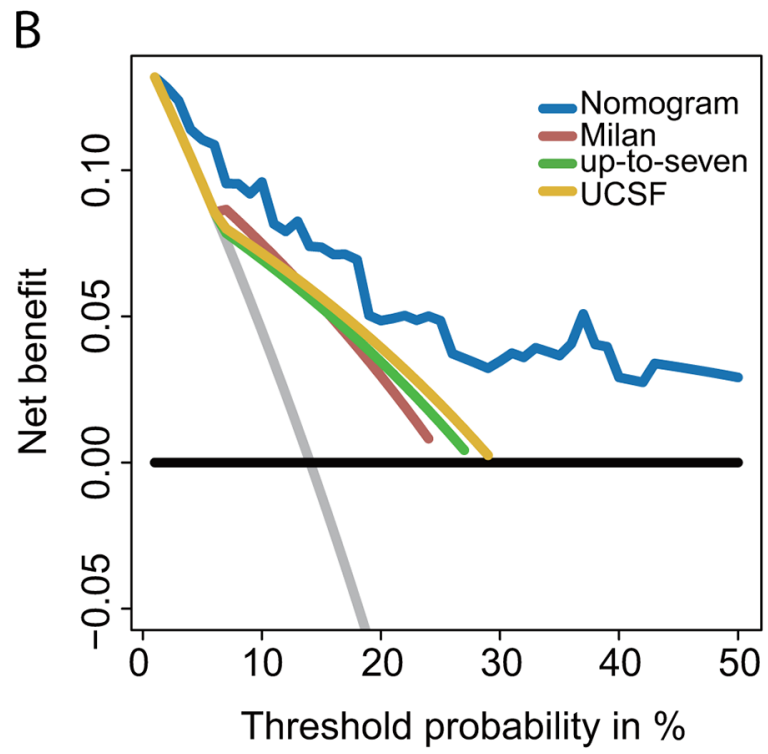

Figure 3: DCA of nomogram and conventional criteria. The net benefits and the threshold probabilities are presented on Y-axis and X-axis, respectively. (A) Comparison within the primary cohort; (B) comparison within the validation cohort; horizontal black line, PM did not occur in any patients; gray line, all the patients developed PM. 


\section{MATERIALS AND METHODS}

\section{Patients}

Between January 2007 and January 2011, patients with HCC who underwent LT at the Ren Ji Hospital (Shanghai, China) composed the primary cohort. The patients who received LT for HCC from February 2007 to December 2011 formed the validation cohort. The data of both cohorts were collected prospectively and analyzed retrospectively. All the surgical procedures and postoperative immunosuppressive treatments were performed as described in our previous study [33]. Transplantation and organ donation in the study was carried out strictly in accordance with the regulations of the Shanghai Organ Transplant Committee and the Declaration of Helsinki. Ethical approval was obtained from the Committee of Ethics at Ren Ji Hospital. Informed consent was acquired before LT. All cadaveric donor tissues involved in the study were obtained from braindead or no-heart beating donors. This study was censored in March 2015.

In the primary cohort, we excluded 23 patients for the following reasons: combination with other tumors $(\mathrm{n}=7 ; 4$ confirmed before and 3 after LT), possible metastatic disease before LT $(n=8)$, possible preoperative pulmonary lesions $(n=3)$, perioperative mortality $(n=3)$, and incomplete data $(\mathrm{n}=2)$. A total of 308 patients met the eligibility criteria and comprised the primary cohort. In the validation cohort, 12 patients were excluded according to the following reasons: combination with other tumors ( $\mathrm{n}=5 ; 3$ confirmed before and 2 after LT), possible metastatic disease before LT $(n=4)$, potential preoperative pulmonary lesions $(\mathrm{n}=1)$, and perioperative mortality $(n=2)$. The validation cohort was composed of 103 patients.

\section{Data collection}

Routine serological examinations of hepatitis B and $\mathrm{C}$ immunology, liver function, prothrombin time (PT), carbohydrate antigen 19-9 (CA19-9), and $\alpha$-fetoprotein (AFP) were performed. Additional examinations included chest radiograph, abdominal ultrasound, magnetic resonance imaging (MRI), and contrast-enhanced computed tomography (CT). Patients with suspected distant metastases received further examination by positron emission tomography (PET). The severity of preoperative disease was evaluated by using the clinical manifestation, radiograph, and serological biomarkers. Preoperative downstaging treatment for $\mathrm{HCC}$ included radiofrequency ablation (RFA), percutaneous ethanol injection (PEI), and transcatheter arterial chemoembolization (TACE).

\section{Follow-up}

Patients were observed monthly in the first 6 months after LT and once every 3 to 6 months thereafter. Routine abdominal ultrasound and chest radiography were performed at each follow-up visit. Other examinations included serum AFP, CA19-9, and liver function tests. When tumor recurrence was suspected, a chest CT scan and contrast-enhanced CT/MRI of the whole abdomen were performed. PM was diagnosed by the following criteria: (a) detection of growing lesions from dynamic chest CT scan and (b) elevated serum AFP level. Other pulmonary lesions were distinguished by a bronchial perfusate test and cytological examination of sputum. Patients who were diagnosed with PM before or simultaneously with extrapulmonary metastases were defined as our subjects.

\section{Management of pulmonary metastasis}

Patients with solitary pulmonary metastasis were referred to thoracic surgeons for consideration of surgical resection. The criteria for surgical resection included the feasibility of complete removal of the lung lesion and sufficient pulmonary function after surgery. In PM patients with concurrent intrahepatic or other extrahepatic recurrence, lung resection performed after complete control of extrapulmonary metastasis. Systemic treatment with sorafenib or conventional chemotherapeutic (doxorubicin and cisplatin) was administered in patients with multifocal disease and unresectable lesions. All available treatment modalities including surgical resection, transarterial chemoembolization, radiofrequency ablation, radiotherapy, and chemotherapy were applied to the extrapulmonary metastases.

\section{Statistical analysis}

The statistical analysis was performed using $\mathrm{R}$ version 3.3.1 for Windows (http://www.r-project.org/) and SPSS 15.0 (SPSS, Chicago, IL). The endpoints of this study were the overall survival (OS), time to recurrence, and the time to PM. Treating extrapulmonary metastasis and death before PM as competing events, we performed a competing risk survival analysis to identify independent factors for PM. The nomogram was built based on these independent factors. The nomogram accuracy was evaluated by $\mathrm{C}$-index and calibration curves. Bootstraps with 2,000 resamples were used to stabilize our results. A decision curve analysis (DCA) was utilized to evaluate the performance of our nomogram. The application and interpretation of this specific method are available online with a step-by-step tutorial $[31,34]$. 


\section{Author contributions}

H.L. and W. P. equally contributed to this paper with conception and design of the study, H.L. and X.D., S.J. wrote the main text and analyzed the data, H.L. and F.M. acquired clinical data. H.L., S.J., X.D., F.M. and Z.J. contributed to critical revision and editing of the manuscript; and X.Q. coordinated the research and approved the final manuscript for publication. All authors reviewed the manuscript.

\section{CONFLICTS OF INTEREST}

The authors declared that they have no conflicts of interest in this work.

\section{FUNDING}

This study was supported by the National Natural Science Foundation of China (No. 81472243), the Key Joint Research Program of Shanghai Health Bureau (2013ZYJB0001), and the Multicenter Clinical Research of Chinese Citizen Donation after Cardiac Death (15411950400).

\section{REFERENCES}

1. Torre LA, Bray F, Siegel RL, Ferlay J, Lortet-Tieulent J, Jemal A. Global cancer statistics, 2012. CA Cancer J Clin. 2015; 65:87-108.

2. Sapisochin G, Bruix J. Liver transplantation for hepatocellular carcinoma: outcomes and novel surgical approaches. Nat Rev Gastroenterol Hepatol. 2017; 14:203-217.

3. Sapisochin G, Goldaracena N, Astete S, Laurence JM, Davidson D, Rafael E, Castells L, Sandroussi C, Bilbao I, Dopazo C, Grant DR, Lázaro JL, Caralt M, et al. Benefit of treating hepatocellular carcinoma recurrence after liver transplantation and analysis of prognostic factors for survival in a large euro-american series. Ann Surg Oncol. 2015; 22:2286-2294.

4. Roayaie S, Frischer JS, Emre SH, Fishbein TM, Sheiner PA, Sung M, Miller CM, Schwartz ME. Long-term results with multimodal adjuvant therapy and liver transplantation for the treatment of hepatocellular carcinomas larger than 5 centimeters. Ann Surg. 2002; 235:533-539.

5. Bates MJ, Farkas E, Taylor D, McFadden PM. Pulmonary resection of metastatic hepatocellular carcinoma after liver transplantation. Ann Thorac Surg. 2008; 85:412-415.

6. Chen F, Sato K, Fujinaga T, Sonobe M, Shoji T, Sakai H, Miyahara R, Bando T, Okubo K, Hirata T, Date H. Pulmonary resection for metastases from hepatocellular carcinoma. World J Surg. 2008; 32:2213-2217.
7. Hwang S, Kim YH, Kim DK, Ahn CS, Moon DB, Kim KH, Ha TY, Song GW, Jung DH, Kim HR, Park GC, Namgoong JM, Yoon SY, et al. Resection of pulmonary metastases from hepatocellular carcinoma following liver transplantation. World J Surg. 2012; 36:1592-1602.

8. Hiraki T, Yamakado K, Ikeda O, Matsuoka T, Kaminou T, Yamagami T, Gobara H, Mimura H, Kawanaka K, Takeda K, Yamashita Y, Inoue Y, Ogawa T, et al. Percutaneous radiofrequency ablation for pulmonary metastases from hepatocellular carcinoma: results of a multicenter study in Japan. J Vasc Interv Radiol. 2011; 22:741-748.

9. Huang J, Yan L, Wu H, Yang J, Liao M, Zeng Y. Is radiofrequency ablation applicable for recurrent hepatocellular carcinoma after liver transplantation? J Surg Res. 2016; 200:122-130.

10. Jang JW, Kay CS, You CR, Kim CW, Bae SH, Choi JY, Yoon SK, Han CW, Jung HS, Choi IB. Simultaneous multitarget irradiation using helical tomotherapy for advanced hepatocellular carcinoma with multiple extrahepatic metastases. Int J Radiat Oncol 9; 74:412-418.

11. Mazzaferro V, Llovet JM, Miceli R, Bhoori S, Schiavo M, Mariani L, Camerini T, Roayaie S, Schwartz ME, Grazi GL, Adam R, Neuhaus P, Salizzoni M, et al. Predicting survival after liver transplantation in patients with hepatocellular carcinoma beyond the Milan criteria: a retrospective, exploratory analysis. Lancet Oncol. 2009; 10:35-43.

12. Mazzaferro V, Regalia E, Doci R, Andreola S, Pulvirenti A, Bozzetti F, Montalto F, Ammatuna M, Morabito A, Gennari L. Liver transplantation for the treatment of small hepatocellular carcinomas in patients with cirrhosis. N Engl J Med. 1996; 334:693-699.

13. Yao FY, Ferrell L, Bass NM, Watson JJ, Bacchetti P, Venook A, Ascher NL, Roberts JP. Liver transplantation for hepatocellular carcinoma: expansion of the tumor size limits does not adversely impact survival. Hepatology. 2001; 33:1394-1403.

14. Bochner BH, Kattan MW, Vora KC; International Bladder Cancer Nomogram Consortium. Postoperative nomogram predicting risk of recurrence after radical cystectomy for bladder cancer. J Clin Oncol. 2006; 24:3967-3972.

15. Wang Y, Li J, Xia Y, Gong R, Wang K, Yan Z, Wan X, Liu G, Wu D, Shi L, Lau W, Wu M, Shen F. Prognostic nomogram for intrahepatic cholangiocarcinoma after partial hepatectomy. J Clin Oncol. 2013; 31:1188-1195.

16. Wierda WG, O'Brien S, Wang X, Faderl S, Ferrajoli A, Do KA, Cortes J, Thomas D, Garcia-Manero G, Koller C, Beran M, Giles F, Ravandi F, et al. Prognostic nomogram and index for overall survival in previously untreated patients with chronic lymphocytic leukemia. Blood. 2007; 109:4679-4685.

17. Xiang ZW, Sun L, Li GH, Maharjan R, Huang JH, Li CX. Progress in the treatment of pulmonary metastases after liver transplantation for hepatocellular carcinoma. World J Hepatol. 2015; 7:2309-2314. 
18. Agopian VG, Harlander-Locke M, Zarrinpar A, Kaldas FM, Farmer DG, Yersiz H, Finn RS, Tong M, Hiatt JR, Busuttil RW. A novel prognostic nomogram accurately predicts hepatocellular carcinoma recurrence after liver transplantation: analysis of 865 consecutive liver transplant recipients. J Am Coll Surg. 2015; 220:416-427.

19. Lee SG, Hwang S, Moon DB, Ahn CS, Kim KH, Sung KB, Ko GY, Park KM, Ha TY, Song GW. Expanded indication criteria of living donor liver transplantation for hepatocellular carcinoma at one large-volume center. Liver Transpl. 2008; 14:935-945.

20. Cillo U, Vitale A, Bassanello M, Boccagni P, Brolese A, Zanus G, Burra P, Fagiuoli S, Farinati F, Rugge M, D'Amico DF. Liver transplantation for the treatment of moderately or well-differentiated hepatocellular carcinoma. Ann Surg. 2004; 239:150-159.

21. Del Gaudio M, Grazi GL, Principe A, Ravaioli M, Ercolani G, Cescon M, Varotti G, Gardini A, Cavallari A. Influence of prognostic factors on the outcome of liver transplantation for hepatocellular carcinoma on cirrhosis: a univariate and multivariate analysis. Hepatogastroenterology. 2004; 51:510-514.

22. Lu Y, Zhu M, Li W, Lin B, Dong X, Chen Y, Xie X, Guo J, $\mathrm{Li}$ M. Alpha fetoprotein plays a critical role in promoting metastasis of hepatocellular carcinoma cells. J Cell Mol Med. 2016; 20:549-558.

23. Li J, Liu Y, Yan Z, Wan X, Xia Y, Wang K, Liu J, Lau WY, Wu M, Shen F. A nomogram predicting pulmonary metastasis of hepatocellular carcinoma following partial hepatectomy. Br J Cancer. 2014; 110:1110-1117.

24. Duvoux C, Roudot-Thoraval F, Decaens T, Pessione F, Badran H, Piardi T, Francoz C, Compagnon P, Vanlemmens C, Dumortier J, Dharancy S, Gugenheim J, Bernard PH, et al. Liver transplantation for hepatocellular carcinoma: a model including alpha-fetoprotein improves the performance of Milan criteria. Gastroenterology. 2012; 143:986-994 e983; quiz e914-985.

25. Chapman WC, Majella Doyle MB, Stuart JE, Vachharajani N, Crippin JS, Anderson CD, Lowell JA, Shenoy S, Darcy $\mathrm{MD}$, Brown DB. Outcomes of neoadjuvant transarterial chemoembolization to downstage hepatocellular carcinoma before liver transplantation. Ann Surg. 2008; 248:617-625.
26. Yao FY, Mehta N, Flemming J, Dodge J, Hameed B, Fix O, Hirose R, Fidelman N, Kerlan RK Jr, Roberts JP. Downstaging of hepatocellular cancer before liver transplant: long-term outcome compared to tumors within Milan criteria. Hepatology. 2015; 61:1968-1977.

27. Callegaro D, Miceli R, Bonvalot S, Ferguson P, Strauss DC, Levy A, Griffin A, Hayes AJ, Stacchiotti S, Pechoux CL, Smith MJ, Fiore M, Dei Tos AP, et al. Development and external validation of two nomograms to predict overall survival and occurrence of distant metastases in adults after surgical resection of localised soft-tissue sarcomas of the extremities: a retrospective analysis. Lancet Oncol. 2016; 17:671-680.

28. Tevis SE, Weber SM, Kent KC, Kennedy GD. Nomogram to predict postoperative readmission in patients who undergo general surgery. JAMA Surg. 2015; 150:505.

29. Wang SJ, Lemieux A, Kalpathy-Cramer J, Ord CB, Walker GV, Fuller CD, Kim JS, Thomas CR Jr. Nomogram for predicting the benefit of adjuvant chemoradiotherapy for resected gallbladder cancer. J Clin Oncol. 2011; 29:4627-4632.

30. Wang SJ, Fuller CD, Kim JS, Sittig DF, Thomas CR Jr, Ravdin PM. Prediction model for estimating the survival benefit of adjuvant radiotherapy for gallbladder cancer. $\mathrm{J}$ Clin Oncol. 2008; 26:2112-2117.

31. Fitzgerald M, Saville BR, Lewis RJ. Decision curve analysis. JAMA. 2015; 313:409-410.

32. Fernandez-Ruiz M, Guerra-Vales JM, Castelbon-Fernandez FJ, Llenas-García J, Caurcel-Díaz L, Colina-Ruizdelgado F. Multiple primary malignancies in Spanish patients with hepatocellular carcinoma: analysis of a hospitalbased tumor registry. J Gastroenterol Hepatol. 2009; 24:1424-1430.

33. Wan P, Zhang J, Long X, Li Q, Xu N, Zhang M, Chen X, Han L, Xia Q. Serum levels of preoperative alphafetoprotein and CA19-9 predict survival of hepatic carcinoma patients after liver transplantation. Eur J Gastroenterol Hepatol. 2014; 26:553-561.

34. Vickers AJ, Elkin EB. Decision curve analysis: a novel method for evaluating prediction models. Med Decis Making. 2006; 26:565-574. 